\title{
Assessment of Sexual Knowledge, Attitude, and Functioning Among Urology Clinic Patients in Imam Reza Hospital of Tehran
}

\author{
Bijan Rezakhaniha, ${ }^{1}$ Soheila Siroosbakht, ${ }^{2}$ Monireh Fahimi, ${ }^{3}$ and Mersad Nazari ${ }^{4}{ }^{*}$ \\ ${ }^{1}$ Department of Urology, AJA University of Medical Sciences, Tehran, IR Iran \\ ${ }^{2}$ Assistant Professor, AJA University of Medical Sciences, Tehran, IR Iran \\ ${ }^{3}$ Graduated in Sociology, Tehran University, Tehran, IR Iran \\ ${ }^{4}$ Graduated in Medicine, AJA University of Medical Sciences, Tehran, IR Iran \\ "Corresponding author: Mersad Nazari, Graduated in Medicine, AJA University of Medical Sciences, Tehran, IR Iran. E-mail: dr_mersad85@yahoo.com
}

Received 2016 July 14; Accepted 2016 August 25.

\begin{abstract}
Background: Sexual relationships are one of the most important and most obsolete aspects of human life since first, and there are many factors which affect sexual knowledge and attitude, and sexual functioning in men and women.

Objectives: The aim of this study was to determine the level of sexual knowledge, attitude, and functioning among urology patients. Methods: This was a cross-sectional descriptive study with stratified random sampling on 84 female and 60 male patients referring to the Urology clinic of Imam Reza hospital, Tehran, Iran. Data were collected using 6 tools including a researcher-made sexual knowledge questionnaire, Dehghani sexual attitude questionnaire, the international index of erectile function(IIEF), and the female sexual functioning index (FSFI), and analyzed by SPSS v.21 software.

Results: The mean scores were $8 \pm 1.3$ out of 11 for sexual knowledge and $47.96 \pm 6.48$ out of 58 for sexual attitude. Only $8.3 \%$ of men had severe sexual dysfunction, but $79.8 \%$ of women had at least one kind of sexual dysfunctions, and pain disorder was the most prevalent one by $53.6 \%$. We found no relationship between age, education, climacteric state, and age at the first sexual experience and any of the major study variables.

Conclusions: Sexual knowledge and attitude, and men's sexual functioning were at good levels in urology patients; however, sexual functioning in this field was remarkably lower in women than general population, and it also had a different pattern: pain disorder was the most prevalent sexual dysfunction.
\end{abstract}

Keywords: Sexual Knowledge, Sexual Attitude, Women’s Sexual Function, Men’s Sexual Function, Urology

\section{Background}

Since a long time ago, human being has started sexual intercourse and reproduction with no systematic teaching. Although sexual desire is an instinctive affair, sexual knowledge, attitude, and behaviors could be taught and also measured.

All information and knowledge about sex and sexual issues including sexual physiology, reproduction, contraception, sexually transmitted diseases, normal sexual behavior and personal and interpersonal sexual behaviors are called "Sexual Knowledge" (1). "Sexual Attitude" is a person's beliefs about sex and sexual issues, which are reflected in his/her behavior and are rooted in his/her cultural perspective and previous experiences (2). According to the latest version of Diagnostic and Statistical Manual of mental disorders (DSM-V), sexual dysfunctions are divided into 3 specific groups for women (female sexual interest/arousal disorder, female orgasmic disorder, and genito-pelvic pain/penetration disorder), 4 specific groups for men (erectile dysfunction, male hypoactive sexual desire disorder, premature ejaculation, and delayed ejacula- tion), Substance/medication-induced sexual dysfunction, other specified sexual dysfunctions, and unspecified sexual dysfunctions $(3,4)$. Premature ejaculation is the most common sexual dysfunction in men younger than 40 Years (5).

Sexual problems are often multifactorial. Sexual disorder is a source of sever marital and family discord (6). The lack of adequate knowledge about sex, wrong attitudes, functional anxiety, spectatoring (it means instead of enjoying your relationship, you are obsessed with evaluation of your performance), and relationship problems are the most important psychological factors about these disorders (7). In this regard, a previous study showed that there is a significant relationship between assertiveness and less self-consciousness (8). It can be seen that people who have low self-esteem are less satisfied with their sexual relationship, leading to sexual dysfunction (9). Many studies have been conducted to assess sexual knowledge, attitude, and function in Iran and all over the world. A lot of studies are about women's sexual dysfunctions in which, the researchers have attributed a great range of prevalence for 
these disorders.

In recent years, researchers have focused on sexual dysfunction especially for women (10). It is interesting that in a research it was known that $37 \%$ of men and $20 \%$ of women who referred to a urogenital clinic in London, after being asked, expressed that they have sexual problems (11).

In this regard, the present study was designed to determine the prevalence of sexual dysfunctions among patients referring to urology clinics and assess their sexual knowledge and attitude.

\section{Methods}

After choosing the study subject and obtaining the ethical approval from the "Ethics Committee", a crosssectional descriptive study was designed. Stratified random sampling was applied. The required sample size for this study was determined using the Cochran's Formula for men and women separately, which led to a sample size of 144, including 84 women and 60 men. The target population was the patients referring to the urology clinic of Imam Reza hospital in Tehran during 2013 - 14. The exclusion criteria were unwillingness to cooperate, age less than 18 , illiteracy, and history of mood disorders, schizophrenia, or using psychotropic medications.

To measure sexual knowledge, a questionnaire was created by the researchers which included 11 True/False questions. This questionnaire was designed with a glance on valid foreign references (12-15), and by considering cultural issues of the Iranian society that was approved by some experts of this field. The internal consistency of the questions seemed acceptable according to the Cronbach's alpha coefficient of 0.98. The sexual knowledge total score in this scale has a range from 0 to 11.

For measuring sexual attitude, we used a tool created by Dehghani et al. (16). This instrument consisted of 3 domains of attitude: emotion, cognition, and behavior. Validity, reliability, and internal consistency of these questions were approved previously. 29 Likert-scale questions were designed with 3 choices scoring 0,1 , and 2 ; thus, the range of the total score was 0 - 58 . In this study, the average number of the control group was 36.85 with a standard error of 0.5 .

For measuring sexual functioning, different tools were used for women and men. Various kinds of instrument have been made for measuring women's sexual function (17). In this study, the Persian version of female sexual function index (FSFI) was used. Validity and reliability of this index was studied and approved by Mohammadi et al. (18) in 2008. Cronbach's alpha was obtained as 0.87 in Foroutan et al. study (19).
For measuring the men's sexual functioning, we used the Persian version of international index of erectile function (IIEF), which is able to evaluate all the aspects of sexual function. This tool was also designed and validated by Rosen et al. in 1997 (20) and the internal consistency of its components with Cronbach's alpha of 0.81 was confirmed by Foroutan et al. in 2008 (19).

In studies dealing with people's private issues, an important point is the way of presenting questionnaires to the patients. In this study, the researcher gave the questionnaires to the participants and convinced them that the questionnaires will be anonymous. We also asked for the permission of using the results in the study. In this study, the confidentiality of information was emphasized and a reference person was introduced to the participants in order to answer their questions. By the way, the patients were assured that answering or not answering the questions had no effect on their treatment process.

\subsection{Statistical Analysis}

The statistical analysis of the data was done using SPSS v.21 software. After computing the patients' scores in sexual knowledge, attitude, and functioning, we calculated the measures of central tendency (mean, median, and mode) as well as the measures of variability (range, standard deviation, and variance), and compared them with the results of previous studies. To compare sexual functioning between men and women, we compared the FSFI and IIEF scores.

To determine the relationship between every two variables, we used suitable statistical tests based on the parameter types. The test included Pearson's coefficient of correlation, Spearman's coefficient of correlation, Independent t-test, and ANOVA followed by a post-hoc test like Tukey.

\section{Results}

The study sample consisted of 84 women and 60 men with the mean age of 31.7 years ranging from 19 to 64.78 patients were married, 55 were single, and 11 categorized themselves separated/widowed/divorced. $2 \%$ had elementary education, $15 \%$ intermediate and upper-intermediate education, $44 \%$ had bachelor degree, and 39\% had masters, PhD, or upper degrees (the illiterates were excluded before). The mean age at the first sexual intercourse was 22 (21 for women and 23.4 for men) with a standard deviation of 5 in the range of $14-51.21 \%$ of the sample were smokers and just 2 women reported menopause.

The sexual knowledge questionnaire consisted of 11 true/false questions on 4 domains of study including sexual physiology, normal sex intercourse, pregnancy and 
contraception, and sexually transmitted diseases. The average score was $8 \pm 1.3$ out of 11 and the correct answers ranged from $21.5 \%$ to $97.9 \%$ for every single question.

Sexual attitude questionnaire consisted of 29 questions on the domain of emotion, cognition, and behavior. The obtained scores and the characteristics of the total score are shown in Table 1.

Table 1. The Participant's Score in Each Domain and Characteristics of the Total Score of Sexual Attitude in Patients Referring to Imam Reza Hospital Urology Clinic

\begin{tabular}{lccc}
\hline & & \multicolumn{1}{c}{ Score } \\
\hline $\begin{array}{l}\text { Average score of the } \\
\text { domain of emotion }\end{array}$ & 18.25 of 24 & $\begin{array}{c}\text { Standard deviation of } \\
\text { scores }\end{array}$ & 6.48 \\
$\begin{array}{l}\text { Average score of the } \\
\text { domain of cognition }\end{array}$ & 18.60 of 20 & Mode & 48 \\
\hline $\begin{array}{l}\text { Average score of the } \\
\text { domain of behavior }\end{array}$ & 11.19 of 12 & The minimum score & 27 \\
$\begin{array}{l}\text { Average of sexual } \\
\text { attitude's total score }\end{array}$ & 47.96 of 58 & The maximum score & 58 \\
\hline
\end{tabular}

The male's sexual function tool (IIEF) consisted of 15 multiple-choice questions on 5 dimensions: erectile function, orgasm, sexual desire, sexual intercourse satisfaction, and general sexual satisfaction. The total score was 50.32 out of 75 with SD of 16.8. A summary of male sexual function classified based on their domain is presented in Figure 1.

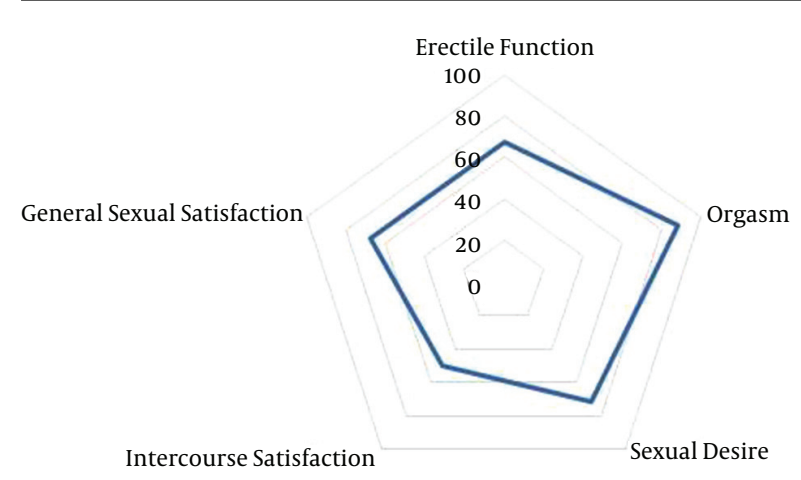

Figure 1. The Percentage of Male Sexual Function Scores, Differentiated by the $5 \mathrm{Di}$ mensions of the IIEF Questionnaire

The tool used to assess female sexual function in this study was the FSFI questionnaire, which studies females' sexual function with 19 questions on 6 dimensions: sexual desires, sexual arousal, vaginal lubrication, orgasm, sexual satisfaction, and pain. More scores show better sexual function. According to balancing the domains, the maximum score for each domain was 6 and for the total scale was 36. The scores lower than the cutoffs are recognized as disorder. Accordingly, the percentage of patients suffering from any (one or more) type of female sexual disorders was $79.8 \%$. The obtained scores based on different dimensions of FSFI are presented in Figure 2.

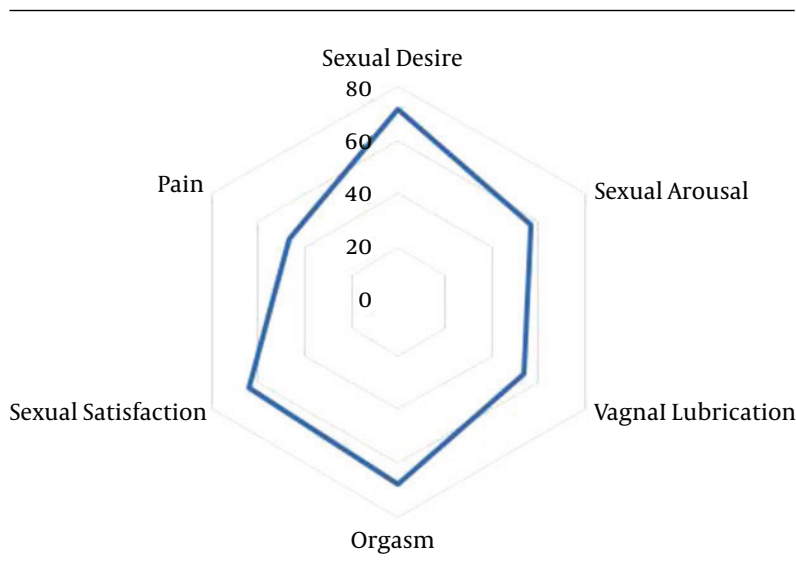

Figure 2. The Percentage of Sexual Function Scores in Women Referring to Imam Reza Hospital Urology Clinic Based on the Six-Dimensional FSFI Questionnaire

Finally, the results of the study indicated a significant relationship among some variables as represented in Table 2 .

\section{Discussion}

From the collected data, it is inferred that the general sexual knowledge of participants is acceptable. However, some of the questions received more wrong answers than the others that need to be further studied. For example, we presented an incorrect statement "a normal sex should last at least 15 minutes" while just 31 respondents did not approve this statement. In other words, about $80 \%$ of the participants believed that a normal sex should last 15 minutes or more. Also, 55.6\% believed that it is impossible to get pregnant during menstruation, and 38.9\% thought that sexual desire will be eliminated in menopausal period. The comparison of the three areas of attitude including emotion, cognition, and behavior showed that the participants got the highest scores in the domain of behavior and the lowest scores in the domain of emotion. Premature egaculation is the most common sexual dysfunction in men (21).

As is evident from the provided figure, the highest scores on IIEF were achieved in the orgasm domain and the lowest scores were in the sexual and general satisfaction domains. The mean score of female sexual function was 21.37 with a standard deviation of 9.11 (in range of 0 - 36). The prevalence of any (one or more) females' sexual dysfunction in this study was $79.8 \%$ that is higher in comparison with the reported prevalence in other studies. 
Table 2. Correlations Among Different Variables in the Study of Sexual Knowledge, Attitude and Function Among Patients Referring to Imam Reza Hospital Urology Clinic

\begin{tabular}{|c|c|c|c|c|c|c|c|c|c|c|}
\hline & $\begin{array}{c}\text { Sexual } \\
\text { Attitude }\end{array}$ & $\begin{array}{l}\text { Males' Sexual } \\
\text { Function }\end{array}$ & $\begin{array}{l}\text { Females' } \\
\text { Sexual } \\
\text { Function }\end{array}$ & Age & Sex & Education & Marital Status & Smoking & $\begin{array}{l}\text { Age at First } \\
\text { Sexual } \\
\text { Relationship }\end{array}$ & $\begin{array}{l}\text { Menopausal } \\
\text { Status }\end{array}$ \\
\hline $\begin{array}{l}\text { Sexual } \\
\text { knowledge }\end{array}$ & $\mathrm{PCC}+0.254$ & $\mathrm{PCC}+0.345$ & $\begin{array}{l}\text { PCC showed no } \\
\text { significant } \\
\text { relationship }\end{array}$ & $\begin{array}{l}\text { PCC showed no } \\
\text { significant } \\
\text { relationship }\end{array}$ & $\begin{array}{l}\text { Ind. samples } \\
\text { t-test showed } \\
\text { significant } \\
\text { relationship (P } \\
=0.001)\end{array}$ & $\begin{array}{l}\text { ANOVA t-test }+ \\
\text { Tukey post hoc } \\
\text { test showed no } \\
\text { significant } \\
\text { relationship }\end{array}$ & $\begin{array}{l}\text { ANOVA t-test }+ \\
\text { Tukey post hoc } \\
\text { test showed } \\
\text { significant } \\
\text { relationship ( } \mathrm{P} \\
=0.004 \text { ) }\end{array}$ & $\begin{array}{l}\text { Ind. samples } \\
\text { t-test showed } \\
\text { significant } \\
\text { relationship (P } \\
=0.038 \text { ) }\end{array}$ & $\begin{array}{l}\text { PCC showed no } \\
\text { significant } \\
\text { relationship }\end{array}$ & $\begin{array}{l}\text { Ind. samples } \\
\text { t-test showed } \\
\text { no significant } \\
\text { relationship }\end{array}$ \\
\hline $\begin{array}{l}\text { Sexual } \\
\text { attitude }\end{array}$ & - & PCC +0.390 & $\mathrm{PCC}+0.413$ & $\begin{array}{l}\text { PCC showed no } \\
\text { significant } \\
\text { relationship }\end{array}$ & $\begin{array}{l}\text { Ind. samples } \\
\text { t-test showed } \\
\text { no significant } \\
\text { relationship }\end{array}$ & $\begin{array}{l}\text { ANOVA t-test }+ \\
\text { Tukey post hoc } \\
\text { test showed no } \\
\text { significant } \\
\text { relationship }\end{array}$ & $\begin{array}{l}\text { ANOVA t-test }+ \\
\text { Tukey post hoc } \\
\text { test showed } \\
\text { significant } \\
\text { relationship ( } P \\
=0.004 \text { ) }\end{array}$ & $\begin{array}{l}\text { Ind. samples } \\
\text { t-test showed } \\
\text { no significant } \\
\text { relationship }\end{array}$ & $\begin{array}{l}\text { PCC showed no } \\
\text { significant } \\
\text { relationship }\end{array}$ & $\begin{array}{l}\text { Ind. samples } \\
\text { t-test showed } \\
\text { no significant } \\
\text { relationship }\end{array}$ \\
\hline $\begin{array}{l}\text { Females' } \\
\text { sexual } \\
\text { function }\end{array}$ & . & . & . & $\begin{array}{l}\text { PCC showed no } \\
\text { significant } \\
\text { relationship }\end{array}$ & . & $\begin{array}{l}\text { ANOVA t-test + } \\
\text { Tukey post hoc } \\
\text { test showed no } \\
\text { significant } \\
\text { relationship }\end{array}$ & $\begin{array}{l}\text { ANOVA t-test + } \\
\text { Tukey post hoc } \\
\text { test showed } \\
\text { significant } \\
\text { relationship (P } \\
=0.007 \text { ) }\end{array}$ & $\begin{array}{l}\text { Ind. samples } \\
\text { t-test showed } \\
\text { no significant } \\
\text { relationship }\end{array}$ & $\begin{array}{l}\text { PCC showed no } \\
\text { significant } \\
\text { relationship }\end{array}$ & $\begin{array}{l}\text { Ind. samples } \\
\text { t-test showed } \\
\text { no significant } \\
\text { relationship }\end{array}$ \\
\hline $\begin{array}{l}\text { Males' sexual } \\
\text { function }\end{array}$ & - & - & - & $\begin{array}{l}\text { PCC showed no } \\
\text { significant } \\
\text { relationship }\end{array}$ & - & $\begin{array}{l}\text { ANOVA t-test + } \\
\text { Tukey post hoc } \\
\text { test showed no } \\
\text { significant } \\
\text { relationship }\end{array}$ & $\begin{array}{l}\text { ANOVA t-test + } \\
\text { Tukey post hoc } \\
\text { test showed no } \\
\text { significant } \\
\text { relationship }\end{array}$ & $\begin{array}{l}\text { Ind. samples } \\
\text { t-test showed } \\
\text { no significant } \\
\text { relationship }\end{array}$ & $\begin{array}{l}\text { PCC showed no } \\
\text { significant } \\
\text { relationship }\end{array}$ & . \\
\hline
\end{tabular}

Abbreviation: PCC, Pearson's coefficient of correlation.

In other studies using similar tool (FSFI), the highest prevalence rate was obtained in Ramezani et al. study by reporting the rate of $64 \%$ (9). Foroutan and Jadid study indicated that $31.5 \%$ of the Iranian women had a kind of sexual dysfunction, which is far away from the rate found in our study (19). However, in that study, FSFI and clinical interview were used to gather data. Mohammadi et al. study achieved the average score of $30.9 \%$ with a standard deviation 3.96 in a healthy control group (18), which is different from our results on urology patients (21.37 with a standard deviation 9.11). Dehkordi et al. study (22) reported a average score of $29.24 \%$ with a standard deviation of 4.16 , which is also different from our results.

In other studies about the areas of disorders, Arman et al. (23) mentioned the desire disorder as the most prevalent one with $49.2 \%$. In Yekeh et al. study (24), the most prevalent disorder was sexual desire disorder (62.4\%), followed by vaginal lubrication disorder (56.5\%) and orgasm disorder (54.3\%). In this study, dyspareunia and vaginismus obtained the percentages of 39.7 and 48.6, respectively. Sexual desire disorder in Dehkordi et al. study (22) was the most prevalent disorder with the lowest score of 3.82 out of 6 on FSFI while the highest score belonged to sexual satisfaction with the value of 5.54 out of 6 . Sexual arousal and orgasm disorder in Mojde et al. study (25) conducted among depressed women were more prevalent (mean scores of 3.07 and 3 out of 6 , respectively) while Rosen et al. and Abdo et al. recognized sexual desire disorder as the most prevalent disorder with $30 \%$ and $26.7 \%$ prevalence rates, respectively $(26,27)$. A review article by Hayes et al. (28) could not achieve a general conclusion about sexual function disorder because of methodologi- cal heterogeneity although it showed that in female sexual dysfunction, the prevalence of sexual desire was averagely $64 \%$, orgasm disorder $35 \%$, sexual arousal disorder $31 \%$, and pain disorder $26 \%$. As can be seen, in majority of studies, sexual desire disorder has been known as the most prevalent disorder. However, in other studies including our study, different results were obtained. For example, Ramazani et al. (9) represented pain disorder as the most prevalent disorder, and Khademi et al. (29) reported sexual arousal as the most common disorder with the prevalence of $80.2 \%$. Ponholzer et al. (30) and Safarinejad et al. (31) comprehensive studies indicated orgasm disorder as the most prevalent disorder with the prevalence rates of $39 \%$ and $37 \%$, respectively.

Our study demonstrated that with an increase in sexual knowledge, the sexual attitude score increases. Pinkerton et al. study (32) showed that an increase in sexual knowledge can cause a healthier and better attitude and performance, and it can also lead to an improvement in males' sexual function. In this study, we observed that an increase in sexual attitude score improves males' sexual function. As is observed in Kinsey, Master, Johnson, and Helen Kaplan' researches during 50s to 80s, an increase in sexual attitude could consequently make an improvement in sexual function and a decrease in sexual disorders' prevalence in western society especially America (16). An increase in sexual attitude score can improve females' sexual function. Therefore, it is reasonable that some experimental studies $(33,34)$ show that counseling on sexual cognitive behaviors can affect females' sexual function.

This study indicated a significant relationship between patients' sexual knowledge and their gender. The average 
score of sexual knowledge was 8.40 among men and 7.69 among women. In our study, the absence of a significant relationship between patients' sexual attitude and their gender was observed, which is in agreement with Dehghani et al. study (16); however, it is not in line with another study (1).

This study showed that there is a significant relationship between patients' sexual knowledge and smoking. It is interesting that the average score of sexual knowledge was higher among smokers than other groups (8.43 vs. 7.87). However, no relationship was found between smoking and sexual attitude and function among women, as seen in other studies $(31,35)$.

Our study showed a significant relationship between sexual knowledge and marital status. Complimentary tests indicated that the highest score of sexual knowledge belonged to the separated/widow/divorced group of patients with the value of 8.45 , followed by the married group with the score of 8.24 and the unmarried group with the score of 7.53. This study also showed a significant relationship between sexual attitude and marital status. In further tests, we indicated that the average score was 52.36 in the separated/widow/divorced group, which was more than the scores of married group (48.67) and unmarried group (46.09). Sexual experience might be an important factor in this relationship. Our study showed a significant relationship between women's marital status and their sexual function; but there was not such relationship among men. The complementary tests showed that the women's sexual function in the married group scored 23.98, which was more than the score of other groups. It means that the more sexual relationships will be more helpful. Contrary to our results, Safarinejad et al. (31) indicated that marriage is associated with females' sexual dysfunction.

\subsection{Conclusions}

We can summarize the results of the study as follows:

- The respondents' sexual knowledge was acceptable; among people with higher sexual knowledge, there were more percentages of men with better sexual function, smokers, and married or previously married individuals (separated/widow/divorced).

- The sexual attitude was at a good level comprising mostly people with higher sexual knowledge, better sexual function, and married or previously married individuals.

- About $80 \%$ of women were suffering from at least one sexual disorder, and pain disorder was the most prevalent one. Sexual performance was better in women with higher sexual attitude and married or previously married individuals.

- About $60 \%$ of men had a good sexual function; the most prevalent disorder was sexual dissatisfaction and males' sexual function was better in those with higher sexual attitude.

- The variables of age, education, age at the first sexual intercourse, and menopausal did not affect other main variables.

- According to the relatively high prevalence of sexual disorders in patients referring to urology clinics, the medical group should focus on them to diagnose and treat sexual dysfunctions.

\section{References}

1. Nooranipoor R, Besharat M, Yousefi E. The relationship between sexual knowledge and attitude with marital satisfaction in young couples. Shahid Beheshti University of Medical Sciences; 2007.

2. Association AP . Psychology Dictionary 2013. Available from: http:// psychologydictionary.org/sexual-attitudes/.

3. Association AP . Diagnostic and Statistical Manual for Mental Disorders. USA: American Psychiatric Press; 2013.

4. IsHak W, Tobia G. DSM-5 Changes in Diagnostic Criteria of Sexual Dysfunctions. Reprod Sys Sex Disord. 2013;2(122).

5. Rezakhanih B, Khoshdael A. Comparative study of therapeutic effect of two medicinal procedures of citaloperam in premature ejaculation. Biosciences Biotechnology Research Asia. 2014;11(2):953-958. doi: $10.13005 /$ bbra/1365.

6. Rezakhaniha B, Safarinejad MA. A survey of prevalence of sexual disorders and risk factors in patient who referred in Urology ward in 501 Army medical center 2004-2005. ANNALS OF MILITARY AND HEALTH SCIENCES RESEARCH. 2008;4(4):1041-1045.

7. Besharat M. Sexual Problems; Classification, Etiology, Assessment and Treatment. Psychother N. 1998;10.

8. Baghbani J. The study of assertiveness and self-consciousness in predicting females' sexual function. Thought Behav J. 2012;7(25).

9. Ramezani M, Dolatian M, Shams J, Alavi H. The relationship between self-esteem and sexual dysfunction and satisfaction in women. 2011

10. Dalpiaz O, Kerschbaumer A, Mitterberger M, Pinggera GM, Colleselli D, Bartsch G, et al. Female sexual dysfunction: a new urogynaecological research field. BJU Int. 2008;101(6):717-21. doi: 10.1111/j.1464410X.2007.07442.x. [PubMed: 18190620].

11. Goldmeier D, Judd A, Schroeder K. Prevalence of sexual dysfunction in new heterosexual attenders at a central London genitourinary medicine clinic in 1998. Sex Transm Infect. 2000;76(3):208-9. [PubMed: 10961200].

12. Hardcastle M. Sex Essentials for Teens 2014. Available from: http:// teenadvice.about.com/cs/sexuallyactive/a/blsexfacts $1 . h$ tm.

13. Hooper A. Can You Pass the Sex Test?. Dorling Kindersley; 2002.

14. Talbot TJ, Langdon PE. A revised sexual knowledge assessment tool for people with intellectual disabilities: is sexual knowledge related to sexual offending behaviour?. J Intellect Disabil Res. 2006;50(Pt 7):52331. doi: 10.1111/j.1365-2788.2006.00801.x. [PubMed: 16774637].

15. Reinisch JM, Beasley R. The Kinsey Institute new report on sex. Macmillan; 1990.

16. Dehghani A, Mohammadkhani P, Younesi J. Influence of sexual skills training on attitude toward sex in young couples. Knowledge Res Appl Psychol. 2008;30:21-38.

17. Kingsberg SA, Iglesia CB, Kellogg S, Krychman ML. Handbook on female sexual health and wellness. Assoc Reprod Health Profession. 2011.

18. Mohammadi KH, Heydari M, Faghihzadeh S. The female sexual function index (FSFI): validation of the Iranian version. Payesh. 2008;7(3):269-78.

19. Foroutan SK, Jadid MM. The prevalence of sexual dysfunction among divorce requested. Daneshvar J Shahed Univ. 2008;16(78):39-44. 
20. Rosen RC, Riley A, Wagner G, Osterloh IH, Kirkpatrick J, Mishra A. The international index of erectile function (IIEF): a multidimensional scale for assessment of erectile dysfunction. Urology. 1997;49(6):82230. [PubMed: 9187685].

21. Rezakhaniha B, Khoshdel AR. Comparative study of therapeutic effects of two medicinal procedures of Fluoxetine in premature ejaculation. JAUMS. 2011;8(34):299-304.

22. Aliakbari DM. Relationship between women sexual function and marital adjustment.J Behav Sci. 2010;4(3):11-2.

23. Arman S, Fahami F, Hasan ZR. A comparative study on women's sexual functioning disorders before and after menopause. ; 2005.

24. Yekeh FL, Goudarzi MR. Prevalence of sexual dysfunction and related factors among married couples in Qazvin.J Huazhong Univ Sci Technol Med Sci. 2009;1(13):49-55.

25. Mojdeh F, Zeyghami S. The Correlation between depression and sexual functioning in married women The second national seminar of health promotion strategies and challenges. Mazandarn University of Medical Sciences; 2011.

26. Rosen RC. Prevalence and risk factors of sexual dysfunction in men and women. Curr Psychiatry Rep. 2000;2(3):189-95. [PubMed: 11122954].

27. Abdo $\mathrm{CH}$, Oliveira WJ, Moreira EJ, Fittipaldi JA. Prevalence of sexual dysfunctions and correlated conditions in a sample of Brazilian women-results of the Brazilian study on sexual behavior (BSSB). Int J Impot Res. 2004;16(2):160-6. doi: 10.1038/sj.ijir.3901198. [PubMed: 14961047].

28. Hayes RD, Bennett CM, Fairley CK, Dennerstein L. What can prevalence studies tell us about female sexual difficulty and dysfunction?. J Sex Med. 2006;3(4):589-95. doi:10.1111/j.1743-6109.2006.00241.x. [PubMed: 16839314].

29. Khademi A, Alleyassin A, Amini M, Ghaemi M. Evaluation of sexual dysfunction prevalence in infertile couples.JSex Med. 2008;5(6):140210. doi: 10.1111/j.1743-6109.2007.00687.x. [PubMed: 18086173].

30. Ponholzer A, Roehlich M, Racz U, Temml C, Madersbacher S. Female sexual dysfunction in a healthy Austrian cohort: prevalence and risk factors. EurUrol. 2005;47(3):366-74. doi:10.1016/j.eururo.2004.10.005. [PubMed: 15716203] discussion 374-5.

31. Safarinejad MR. Female sexual dysfunction in a population-based study in Iran: prevalence and associated risk factors. Int J Impot Res. 2006;18(4):382-95. doi: 10.1038/sj.ijir.3901440. [PubMed:16395324].

32. Pinkerton SD, Abramson PR. Is risky sex rational?. J Sex Res. 1992;29(4):561-8. doi: 10.1080/00224499209551667.

33. Rahimi E, Shafiabadi A, Yunesi F. The effect of sexual cognitivebehavioral therapy on females' sexual knowledge, sexual attitude, and sexual self-confidence. A case study in Shiraz, Iran. Armaghane Danesh. 2009;14(3):103-11.

34. Rezakhaniha B, Sirosbakht S. Efficacy of selective serotonin reuptake inhibitor (SSRI) in patient with premature ejaculation. Int J Reprod BioMed. 2010;8(2):55-9.

35. Cayan S, Akbay E, Bozlu M, Canpolat B, Acar D, Ulusoy E. The prevalence of female sexual dysfunction and potential risk factors that may impair sexual function in Turkish women. Urol Int. 2004;72(1):52-7. doi: 10.1159/000075273. [PubMed:14730166]. 